\title{
Increasing numbers of nonaneurysmal subarachnoid hemorrhage in the last 15 years: antithrombotic medication as reason and prognostic factor?
}

\author{
Juergen Konczalla, MD, Sepide KashefiolasI, MD, Nina Brawanski, MD, Christian Senft, MD, PhD, \\ Volker Seifert, MD, PhD, and Johannes Platz, MD \\ Department of Neurosurgery, Goethe University Hospital, Frankfurt, Germany
}

\begin{abstract}
OBJECTIVE Subarachnoid hemorrhage $(\mathrm{SAH})$ is usually caused by a ruptured intracranial aneurysm, but in some patients no source of hemorrhage can be detected. More recent data showed increasing numbers of cases of spontaneous nonaneurysmal SAH (NASAH). The aim of this study was to analyze factors, especially the use of antithrombotic medications such as systemic anticoagulation or antiplatelet agents (aCPs), influencing the increasing numbers of cases of NASAH and the clinical outcome.
\end{abstract}

METHODS Between 1999 and 2013, 214 patients who were admitted to the authors' institution suffered from NASAH, $14 \%$ of all patients with SAH. Outcome was assessed according to the modified Rankin Scale (mRS) at 6 months. Risk factors were identified based on the outcome.

RESULTS The number of patients with NASAH increased significantly in the last 15 years of the study period. There was a statistically significant increase in the rate of nonperimesencephalic (NPM)-SAH occurrence and aCP use, while the proportion of elderly patients remained stable. Favorable outcome (mRS $0-2$ ) was achieved in $85 \%$ of cases, but patients treated with aCPs had a significantly higher risk for an unfavorable outcome. Further analysis showed that elderly patients, and especially the subgroup with a Fisher Grade 3 bleeding pattern, had a high risk for an unfavorable outcome, whereas the subgroup of NPM-SAH without a Fisher Grade 3 bleeding pattern had a favorable outcome, similar to perimesencephalic (PM)-SAH.

CONCLUSIONS Over the years, a significant increase in the number of patients with NASAH has been observed. Also, the rate of aCP use has increased significantly. Risk factors for an unfavorable outcome were age $>65$ years, Fisher Grade 3 bleeding pattern, and aCP use. Both "PM-SAH" and "NPM-SAH without a Fisher Grade 3 bleeding pattern" had excellent outcomes. Patients with NASAH and a Fisher Grade 3 bleeding pattern had a significantly higher risk for an unfavorable outcome and death. Therefore, for further investigations, NPM-SAH should be stratified into patients with or without a Fisher Grade 3 bleeding pattern. Also, cases of spontaneous SAH should be stratified into NASAH and aneurysmal SAH.

http://thejns.org/doi/abs/10.3171/2015.5.JNS15161

KEY WORDS nonaneurysmal subarachnoid hemorrhage; nonperimesencephalic; anticoagulation; antiplatelet agent;

Fisher Grade 3; vascular disorders

$\mathrm{S}$ UBARACHNOID hemorrhage (SAH) is usually caused by intracranial aneurysm rupture. However, in up to $20 \%$ of patients with SAH, results of cerebral angiography, CT, and MRI are negative for aneurysms or other vascular malformations..$^{2,7,11}$ More recent data show an increasing number of cases of spontaneous $\mathrm{SAH}^{18,24}$ as well as nonaneurysmal SAH (NASAH). ${ }^{15,16}$ Long-term dipyridamole and warfarin use were associated with an increased risk for aneurysmal SAH (aSAH), whereas the data for low-dose acetylsalicylic acid (LDA) were inconsistent. ${ }^{10,14,21}$ Therefore, we analyzed our institutional database for patients suffering from angiography-negative $\mathrm{SAH}$. The aim of the study was to identify risk factors for the increase of NASAH as well as analyze outcome.

ABBREVIATIONS aCP = systemic anticoagulation or antiplatelet agent; aSAH = aneurysmal subarachnoid hemorrhage; $\mathrm{CVS}=$ cerebral vasospasm; $\mathrm{DCI}=$ delayed cerebral infarction; DSA = digital subtraction angiography; LDA = low-dose acetylsalicylic acid; mRS = modified Rankin Scale; NASAH = nonaneurysmal SAH; NPM = nonperimesencephalic; PM = perimesencephalic; SAH = subarachnoid hemorrhage; WFNS = World Federation of Neurosurgical Societies.

SUBMITTED January 23, 2015. ACCEPTED May 14, 2015.

INCLUDE WHEN CITING Published online November 13, 2015; DOI: 10.3171/2015.5.JNS15161. 


\section{Methods}

All patients $(n=1493)$ with spontaneous SAH between 1999 and 2013 admitted to our institution were screened. Patients with trauma-related SAH and patients in whom the bleeding sources were determined to be an aneurysm or vascular malformation were excluded from the study. ${ }^{15,16} \mathrm{SAH}$ was diagnosed by CT or lumbar puncture. Patient characteristics, treatments, radiological features, and outcomes were prospectively entered into our neurovascular database. The study was approved by the local ethics committee.

All patients underwent angiography and, after it became available in 2002, 3D digital subtraction angiography (DSA) of at least 4 vessels was also used to rule out intracranial bleeding sources. ${ }^{12}$ Generally, the angiography was repeated once: in patients with Fisher Grade 3 bleeding pattern, regularly 14 days after the ictus, and in some patients again at 2 months after the ictus. Additionally, spinal MRI was performed to rule out a spinal bleeding source.

On admission, patients were divided into good admission status (World Federation of Neurosurgical Societies [WFNS] Grades I-III) and poor admission status (WFNS Grades IV-V). Outcome was assessed according to the modified Rankin Scale (mRS) after 6 months and stratified into favorable (mRS Score 0-2) and unfavorable (mRS Score 3-6).

We defined a perimesencephalic (PM) hemorrhage according to van Gijn et al. ${ }^{23}$ and Rinkel et al. ${ }^{19}$ if the hemorrhage was located in front of the brainstem, mainly in the interpeduncular cistern. In nonperimesencephalic (NPM) hemorrhages, blood was not located mainly in the interpeduncular cistern but in the basal cisterns, Sylvian cistern, interhemispheric cistern, or convexity, or the patient had CT-negative and lumbar puncture-positive bleeding. We also stratified NPM-SAH cases into patients with a Fisher Grade 3 bleeding pattern or a non-Fisher Grade 3 bleeding pattern.

\section{Statistical Analysis}

Data analysis was performed using the computer software package SPSS version 22 (IBM Corp.). Unpaired ttests were used for parametric statistics. Categorical variables were analyzed in contingency tables using Fisher's exact test. For trend statistics, the Mantel-Haenszel test was used. Results with $\mathrm{p} \leq 0.05$ were considered statistically significant. Due to the low number of cases, we divided the study period into 3-year intervals to be able to compare the data.

\section{Results}

\section{Patient Characteristics}

Between 1999 and 2013, 214 patients who were admitted to our institution were found to have NASAH based on initial diagnostic workup (see flow diagram show in Fig. 1). Patients' characteristics, including bleeding type, age, sex, use of antithrombotic medications such as systemic anticoagulation or antiplatelet agents (aCPs), hypertension, and clinical outcome are presented in detail in Table 1.

In the baseline interval from 1999 to 2001,20 pa- tients presented with a NASAH. In the following 3 years (2002-2004), 70\% more patients $(n=34)$ were found to have NASAH. The number of NASAH cases increased significantly over the study intervals to $65(225 \%)$ in the last interval (2011-2013) (Fig. 2; Table 2). Over the entire study period, the ratio of patients with NASAH compared with all patients with SAH increased from 9\% to over $20 \%$. Trend statistics showed a highly significant linear trend for this increase in NASAH ( $<<0.001$; Fig. 3). The proportion of patients older than 65 years (approximately 25\%; Table 2) was stable, and statistics showed no significant trend toward a higher admission rate.

We identified elderly patients, aCP use, and Fisher Grade 3 bleeding pattern as significant prognostic factors for an unfavorable outcome ( $\mathrm{p}<0.01$; Table 3$)$.

\section{SAH Pattern on Initial CT Scan}

Overall, $46 \%$ of the patients had a PM-SAH and 54\% of patients suffered from NPM-SAH (Table 1). Of all NASAH cases, the proportion of patients with NPM-SAH increased significantly over the study intervals, from $50 \%$ in 1999 2001 to $71 \%$ in $2011-2013$ ( $p<0.05$ ), whereas the rate of PM-SAH decreased significantly from $50 \%$ to $29 \%$. For patients with NPM-SAH, only a trend toward an unfavorable outcome was detected, but for the subgroup of patients with a Fisher Grade 3 bleeding pattern, a significantly higher mortality rate $(p<0.01)$ and a significantly higher risk for an unfavorable outcome were detected ( $\mathrm{p}<0.01$; Table 3 ). Also, the observation of Fisher Grade 3 bleeding patterns increased over the study intervals, from a rate of $15 \%$ to $26 \%$, but did not achieve statistical significance.

\section{Arterial Hypertension}

In the first study interval, $30 \%$ of the patients had hypertension. In the subsequent years, the rate of hypertension slightly increased to $51 \%$ of patients, which was not a significant trend ( $p>0.1$; Fig. 2; Table 2). Hypertension neither influenced the outcome nor the type of bleeding (PM- or NPM-SAH; Tables 1 and 3).

\section{Use of Systemic Anticoagulation or Antiplatelet Agents}

The use of aCPs increased steadily and significantly, from $5 \%$ of cases in 1999-2001 to $32 \%$ of cases in 20112013 (Fig. 2; Table 2). Significantly more patients with NPM-SAH were treated with aCPs $(\mathrm{p}<0.01$; Table 1$)$, and these patients seem to have higher rates of cerebral vasospasm (CVS) and delayed cerebral infarctions (DCIs) (Table 4). Additionally, patients who received aCPs had a significantly higher mortality rate $(21 \%$ vs $5 \%$ without aCP; $p<0.01$; Table 4) and a significantly lower chance for favorable outcome (mRS $0-2,63 \%$ vs $91 \%$ without aCP; $p$ $<0.0001$; Table 3).

\section{Discussion}

Subarachnoid hemorrhage without identification of a bleeding source is/was rare compared with aSAH and is assumed to have a good outcome. , $^{4,20,22}$ However, recent investigations have shown this condition increasing. ${ }^{15,16,18}$ Our institutional data from the last 15 years was analyzed, 


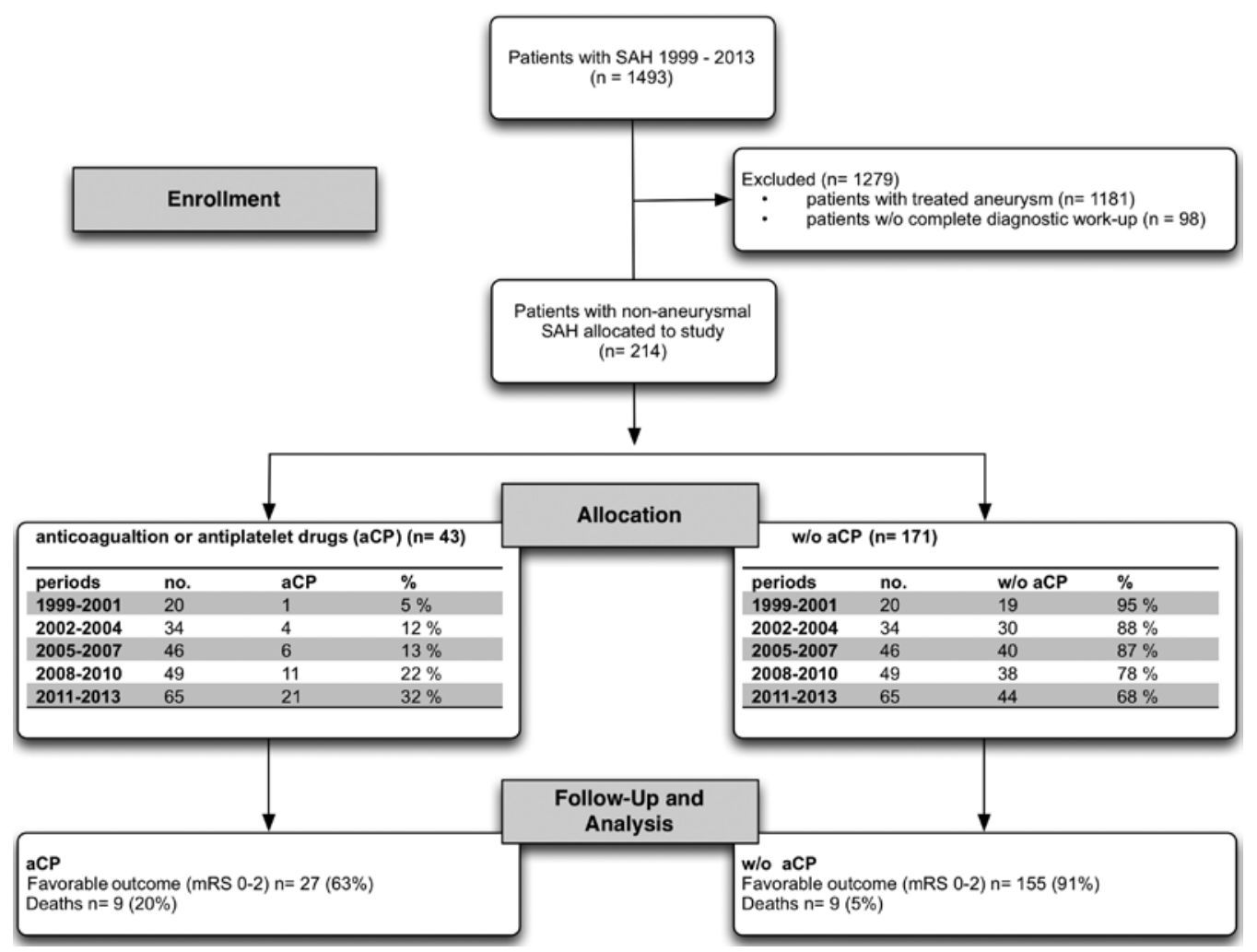

FIG. 1. Flow diagram showing detailed information about patient enrollment, allocation, follow-up, and analysis.

and 214 patients suffering from angiography-negative $\mathrm{SAH}$ were identified. Most of the patients achieved a favorable outcome, but in the last years, we have observed a shift in the profile of patient characteristics. An increasing number of patients who were undergoing treatment with aCPs and exhibiting greater bleeding patterns (Fisher Grade 3) were admitted to our hospital.

\section{Incidence of NASAH and SAH Pattern}

Overall, in the present series, a favorable outcome was achieved in $85 \%$ of the patients with NASAH, which is comparable to other reported data. ${ }^{4,11}$ However, despite technical advancements in DSA, MRI, and CT technology over the study period, the number of patients with NASAH has increased significantly (Fig. 3). Also, the SAH bleeding pattern has changed significantly over the period intervals (Fig. 1). Whereas in the first interval 50\% of the patients suffered from PM-SAH, in the last period (2011-2013) only 29\% had PM-SAH. Meanwhile, the observation of Fisher Grade 3 bleeding patterns increased from $15 \%$ (1999-2001) to $26 \%$ (2011-2013). In patients suffering from NASAH, favorable outcomes were significantly associated with the SAH pattern on initial CT. ${ }^{8,25}$ A Fisher Grade 3 bleeding pattern represented a

TABLE 1. Characteristics of 214 patients with nonaneurysmal SAH stratified by SAH location (perimesencephalic vs nonperimesencephalic)*

\begin{tabular}{|c|c|c|c|c|c|}
\hline \multirow[b]{2}{*}{ Characteristic } & \multirow[b]{2}{*}{ NASAH } & \multicolumn{2}{|c|}{ Type of NASAH } & \multirow{2}{*}{$\begin{array}{c}\text { p Value } \dagger \\
\text { PM- vs NPM-SAH }\end{array}$} & \multirow[b]{2}{*}{ OR $(95 \% \mathrm{Cl})$} \\
\hline & & PM-SAH & NPM-SAH & & \\
\hline No. of pts & 214 & $98(46)$ & $116(54)$ & & \\
\hline Mean age \pm SD (yrs) & $57 \pm 14$ & $55 \pm 12$ & $58 \pm 15$ & NS & \\
\hline Female & $79(37)$ & $30(31)$ & $49(42)$ & NS & \\
\hline HTN & $93(43)$ & $37(38)$ & $56(48)$ & NS & \\
\hline $\mathrm{aCP}$ & $43(20)$ & $11(11)$ & $32(28)$ & $<0.01$ & $3.0(1.4-6.4)$ \\
\hline Fav outcome & $182(85)$ & $88(90)$ & $94(81)$ & NS & \\
\hline Death & $18(8)$ & $7(7)$ & $11(9)$ & NS & \\
\hline
\end{tabular}

Fav outcome = favorable outcome; HTN = arterial hypertension; NS = not significant $(p>0.05)$; pts = patients.

* Values are $n(\%)$ unless otherwise indicated.

† Unpaired t-test for parametric statistics and Fisher's exact test for categorical variables. 


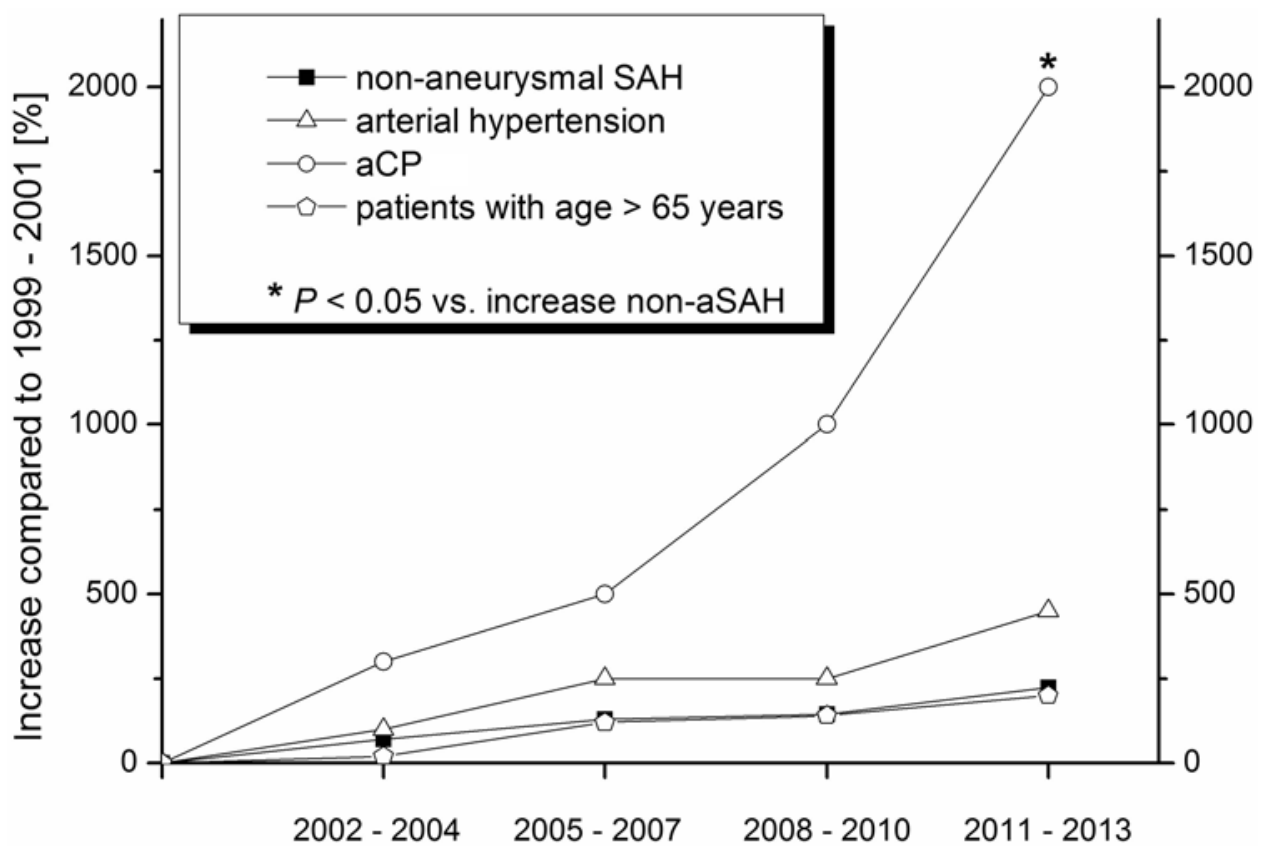

FIG. 2. Graph showing percent increase from interval 1999-2001 throughout the study period of patients with NASAH, with arterial hypertension, aCP use, and patients $>65$ years. In all groups the absolute number increased. Only a slight increase was detected for hypertension and patients $>65$ years (similar to the increase of NASAH), whereas the rate of patients treated with aCP increased significantly.

significantly higher risk for an unfavorable outcome (OR 3.2; Table 3) and death (OR 3.0) compared with a NPM non-Fisher Grade 3 bleeding pattern, as described earlier. ${ }^{13,16,25}$ A comparison between PM- and NPM-SAH revealed a trend towards an unfavorable outcome for NPM-SAH $(p=0.09)$, which supports recent data. ${ }^{1,16,25}$ The NPM-SAH group without a Fisher Grade 3 bleeding pattern had similar and often favorable outcomes (87\%) compared with the PM-SAH group (90\%; Table 1). Accordingly, patients with an NPM-SAH and without a Fisher Grade 3 bleeding pattern also had a significantly better outcome compared with patients with NPM-SAH and a Fisher Grade 3 bleeding pattern ( $\mathrm{p}<0.05$, OR 2.7). Patients with a Fisher Grade 3 bleeding pattern had a significantly higher mortality rate compared with patients with NPM-SAH and without a Fisher Grade 3 bleeding pattern $(\mathrm{p}=0.05$, OR 3.7). Therefore, we recommend for further investigations a more detailed analysis of NPM-
SAH, stratified to NPM-SAH with and without a Fisher Grade 3 bleeding pattern.

Whereas the use of newer CT scanners, offering greater detection capability, might be a reason for the increase of NPM-SAH, older CT scanners were also able to detect especially large bleeding patterns (Fisher Grade 3), which, nevertheless, are detected more often at present. Possible reasons for the increase of NPM-SAH may be hypertension and $\mathrm{aCP}$ use, but this could also be purely coincidental.

\section{Prognostic Factors}

As in other studies,${ }^{15}$ in our investigations, elderly patients had a significantly higher risk for an unfavorable outcome (Table 3), but the proportion of elderly patients remained stable (approximately 25\%; Table 2).

Forty-three percent of the patients had arterial hyper-

TABLE 2. Increase in NASAH, arterial hypertension, and aCP treatment throughout the study period

\begin{tabular}{|c|c|c|c|c|c|c|c|c|c|c|c|c|}
\hline $\begin{array}{c}\text { Study } \\
\text { Intervals }\end{array}$ & $\begin{array}{l}\text { No. of } \\
\text { Pts w/ } \\
\text { NASAH }\end{array}$ & $\begin{array}{c}\% \mathrm{Pt} \\
\text { Increase }\end{array}$ & $\begin{array}{l}\text { HTN, } \\
n(\%)\end{array}$ & $\begin{array}{c}\% \mathrm{Pt} \\
\text { Increase* }\end{array}$ & $\begin{array}{c}p \\
\text { Valuet }\end{array}$ & $\begin{array}{l}\text { Age }>65 \\
\text { Yrs, n (\%) }\end{array}$ & $\begin{array}{c}\% \mathrm{Pt} \\
\text { Increase* }\end{array}$ & $\begin{array}{c}p \\
\text { Value† }\end{array}$ & $\begin{array}{l}\text { Pts Treated } \\
\text { w/ aCP, } \\
\text { n (\%) }\end{array}$ & $\begin{array}{c}\% \mathrm{Pt} \\
\text { Increase* }\end{array}$ & $\begin{array}{c}\mathrm{p} \\
\text { Valuet }\end{array}$ & $\begin{array}{c}\text { OR } \\
(95 \% \mathrm{Cl})\end{array}$ \\
\hline 1999-2001 & 20 & & $6(30)$ & & & $5(25)$ & & & $1(5)$ & & & \\
\hline 2002-2004 & 34 & 70 & $12(35)$ & 100 & NS & $6(18)$ & 20 & NS & $4(12)$ & 300 & NS & \\
\hline 2005-2007 & 46 & 130 & $21(46)$ & 250 & NS & $11(24)$ & 120 & NS & $6(13)$ & 500 & NS & \\
\hline 2008-2010 & 49 & 145 & $21(43)$ & 250 & NS & $12(24)$ & 140 & NS & $11(22)$ & 1000 & NS & \\
\hline 2011-2013 & 65 & 225 & $33(51)$ & 450 & NS & $16(25)$ & 200 & NS & $21(32)$ & 2000 & $<0.05$ & $9.1(1.1-72)$ \\
\hline
\end{tabular}

* Calculated as increase relative to study interval 1999-2001.

† Unpaired t-test for parametric statistics and Fisher's exact test for categorical variables versus study interval 1999-2001. 


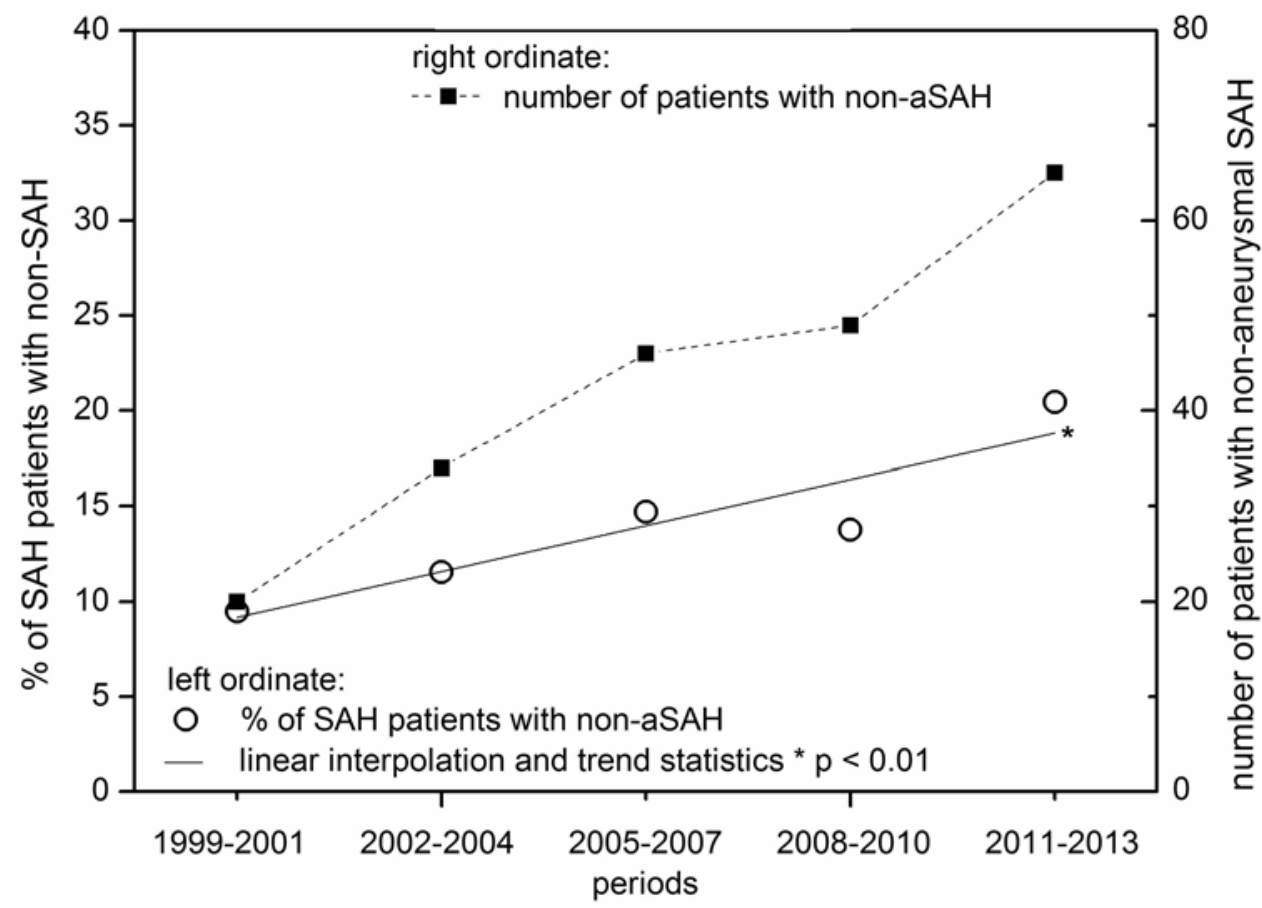

FIG. 3. Graph showing increase in percentage and numbers of patients with NASAH among all patients with SAH throughout the study period. The left ordinate shows the percentage of patients with NASAH (circles) and a linear interpolation (significant increase over the study intervals; $p<0.01$ ). The right ordinate shows the absolute number of patients with NASAH (squares) admitted to our hospital.

tension, which is comparable to other reported data. ${ }^{3,9}$ Over the study intervals, the rate of patients with hypertension increased nonsignificantly (Fig. 2; Table 2). The outcome and mortality rate were similar for patients with or without hypertension as those observed in other reports. ${ }^{8,15}$ Hypertension in aSAH is associated with unfavorable outcome, ${ }^{9}$ whereas in NASAH, it seems not to be a prognostic factor (Table 3 ).

Another factor that may account for the increasing number of patients with NASAH and the enlarging amount of visible blood could be aCP use. The rate of patients being treated with aCPs has increased significantly (from 5\% to 32\%; Figs. 2 and 3; Table 2), but data for NASAH are scarce and mostly only describe higher blood volume and rebleeding rates, resulting in worse admission status and worse outcome. ${ }^{4,13,25}$ Data for aSAH also remain scarce and describe a worse outcome ${ }^{13}$ or nonreduced 30-day case fatality. ${ }^{9}$

However, aCP use was significantly higher in the NPMSAH group compared with the PM-SAH group (28\% vs $11 \% ; \mathrm{p}<0.01$; Table 1). The slightly increased rate of CVS and DCI with aCP use could also be an indication for higher amounts of bleeding, without reaching statistical significance. Nonetheless, the population of patients treated with aCPs had a significantly higher mortality rate and a 5.7-times higher risk for an unfavorable outcome. Therefore, this indicates that aCP use is, at least, a prognostic factor.

\section{Reasons for Increased Numbers of NASAH}

The number of patients with NASAH increased sig-

TABLE 3. Prognostic factors for outcome*

\begin{tabular}{|c|c|c|c|c|}
\hline Characteristic & Favorable Outcome & Unfavorable Outcome & p Value vs Favorable Outcome $†$ & OR $(95 \% \mathrm{Cl})$ \\
\hline No. of pts & $182(85)$ & $32(15)$ & & \\
\hline Mean age \pm SD (yrs) & $55 \pm 13$ & $68 \pm 11$ & $<0.0001$ & \\
\hline Female & $64(35)$ & $15(47)$ & NS & \\
\hline HTN & $75(41)$ & $18(56)$ & NS & \\
\hline NPM-SAH w/o Fisher Grade 3 & $65(36)$ & $10(31)$ & NS & \\
\hline Fisher Grade 3 & $29(16)$ & $12(38)$ & $<0.01$ & $3.2(1.4-7.2)$ \\
\hline aCP use & $27(15)$ & $16(50)$ & $<0.0001$ & $5.7(2.6-12.8)$ \\
\hline
\end{tabular}

* Values are $n(\%)$ unless otherwise indicated.

$\dagger$ Unpaired t-test for parametric statistics and Fisher's exact test for categorical variables. 
TABLE 4. Rates of cerebral vasospasm, delayed cerebral ischemia, and mortality in patients with NASAH depending on use of aCP*

\begin{tabular}{cccccc}
\hline Characteristic & All Pts $(n=214)$ & w/o aCP $(n=171)$ & w/ aCP $(n=43)$ & $p$ Value & OR $(95 \%$ Cl) \\
\hline CVS & $42(20)$ & $32(19)$ & $10(23)$ & NS & \\
\hline DCl & $30(14)$ & $22(13)$ & $8(19)$ & NS & \\
\hline Death & $18(8)$ & $9(5)$ & $9(21)$ & $<0.05$ & $4.8(1.8-12.9)$ \\
\hline
\end{tabular}

* Values are $\mathrm{n}(\%)$ unless otherwise indicated.

$\dagger$ Fisher's exact test.

nificantly over the study intervals (225\%) (Fig. 2; Table 2). Long-term dipyridamole and warfarin use were associated with an increased risk for aSAH, whereas the data for low-dose LDA in aSAH were inconsistent. ${ }^{10,14,21}$ Also, a recently published meta-analysis showed a higher risk for subdural hematoma in patients using vitamin $\mathrm{K}$ antagonists or LDA. ${ }^{5,6}$ In this study, the significant increase of NASAH was associated with a significant increase of use of aCPs (2000\%; $p<0.05$; Table 2), which was also associated with an increased rate of NPM (Table 1). Also, it is known that aCP use is associated with an increased $\mathrm{SAH}$ volume. ${ }^{17}$ Altogether, this suggests that aCP use may play an important role in the increase of NASAH.

\section{Limitations}

The study has several limitations. It is a retrospective, single-center, statistical analysis, but data were collected prospectively. Due to the retrospective design, the typical restrictions exist, such as the lack of data not documented initially in the medical records. Nonetheless, given that NASAH is a rare condition, the cohort is very large and also exhibited trend statistics showing a significant increase. Due to the low number of cases, we divided the study period into 3-year intervals to allow for comparison of the data, but statistics showed a significant trend in both modalities, per-period and per-year analysis. Therefore, the data seem to be reliable and valid.

However, the numbers of patients using aCPs are still low, and, therefore, it is not advisable to create subgroups to obtain more valid data for a causal relationship. No patients in this cohort received any of the newly available oral anticoagulants. The reasons for the observed increase of frequency and severity of NASAH could be coincidental to aCP use, and the exact pathogenic mechanism of NASAH is still unclear. Therefore, a combination of hypertension and aCP use may play a role, but a causal relationship cannot, thus far, be proven. Data from other centers are necessary to confirm our findings; however, for this rare condition, the cohort may be considered large. Thus, we advise that other institutes examine their patient cohort with these considerations in mind.

\section{Conclusions}

The number of patients in our cohort with NASAH has been increasing significantly over the last 15 years. Therefore, further studies investigating increasing number of cases of spontaneous SAH should stratify between NA$\mathrm{SAH}$ and aSAH. Also, we identified significantly higher rates of aCP use, different types of bleeding (higher in- cidence of NPM-SAH), and higher volumes of bleeding (higher incidence of Fisher Grade 3 bleeding pattern). The use of aCPs was a negative prognostic factor and was associated with a significantly worse outcome and a higher mortality rate, whereas hypertension was not a prognostic factor. Also, elderly patients had a higher risk for an unfavorable outcome.

Patients with an NPM-SAH without Fisher Grade 3 bleeding pattern experienced an excellent outcome, similar to that of PM-SAH patients, whereas patients with a NPM-SAH with Fisher Grade 3 bleeding pattern had a high risk for an unfavorable outcome and death. Further investigations should stratify NPM-SAH to patients with or without Fisher Grade 3 bleeding pattern.

\section{Acknowledgments}

We thank Marina Heibel and Anne Sicking for their excellent technical support.

\section{References}

1. Andaluz N, Zuccarello M: Yield of further diagnostic workup of cryptogenic subarachnoid hemorrhage based on bleeding patterns on computed tomographic scans. Neurosurgery 62:1040-1047, 2008

2. Bakker NA, Groen RJ, Foumani M, Uyttenboogaart M, Eshghi OS, Metzemaekers JD, et al: Repeat digital subtraction angiography after a negative baseline assessment in nonperimesencephalic subarachnoid hemorrhage: a pooled data meta-analysis. J Neurosurg 120:99-103, 2014

3. Beseoglu K, Pannes S, Steiger HJ, Hänggi D: Long-term outcome and quality of life after nonaneurysmal subarachnoid hemorrhage. Acta Neurochir (Wien) 152:409-416, 2010

4. Boswell S, Thorell W, Gogela S, Lyden E, Surdell D: Angiogram-negative subarachnoid hemorrhage: outcomes data and review of the literature. J Stroke Cerebrovasc Dis 22:750757, 2013

5. Connolly BJ, Pearce LA, Hart RG: Vitamin K antagonists and risk of subdural hematoma: meta-analysis of randomized clinical trials. Stroke 45:1672-1678, 2014

6. Connolly BJ, Pearce LA, Kurth T, Kase CS, Hart RG: Aspirin therapy and risk of subdural hematoma: meta-analysis of randomized clinical trials. J Stroke Cerebrovasc Dis 22:444-448, 2013

7. Elhadi AM, Zabramski JM, Almefty KK, Mendes GAC, Nakaji P, McDougall CG, et al: Spontaneous subarachnoid hemorrhage of unknown origin: hospital course and longterm clinical and angiographic follow-up. J Neurosurg 122:663-670, 2015

8. Fontanella M, Rainero I, Panciani PP, Schatlo B, Benevello C, Garbossa D, et al: Subarachnoid hemorrhage and negative angiography: clinical course and long-term follow-up. Neurosurg Rev 34:477-484, 2011 
9. Garbe E, Kreisel SH, Behr S: Risk of subarachnoid hemorrhage and early case fatality associated with outpatient antithrombotic drug use. Stroke 44:2422-2426, 2013

10. García-Rodríguez LA, Gaist D, Morton J, Cookson C, González-Pérez A: Antithrombotic drugs and risk of hemorrhagic stroke in the general population. Neurology 81:566574, 2013

11. Gupta SK, Gupta R, Khosla VK, Mohindra S, Chhabra R, Khandelwal N, et al: Nonaneurysmal nonperimesencephalic subarachnoid hemorrhage: is it a benign entity? Surg Neurol 71:566-572, 2009

12. Horstman P, Linn FHH, Voorbij HA, Rinkel GJ: Chance of aneurysm in patients suspected of SAH who have a 'negative' CT scan but a 'positive' lumbar puncture. J Neurol 259:649_ 652,2012

13. Hui FK, Schuette AJ, Moskowitz SI, Gupta R, Spiotta AM, Obuchowski NA, et al: Antithrombotic states and outcomes in patients with angiographically negative subarachnoid hemorrhage. Neurosurgery 68:125-131, 2011

14. Hui FK, Tumialán LM, Tanaka T, Cawley CM, Zhang YJ: Clinical differences between angiographically negative, diffuse subarachnoid hemorrhage and perimesencephalic subarachnoid hemorrhage. Neurocrit Care 11:64-70, 2009

15. Konczalla J, Platz J, Schuss P, Vatter H, Seifert V, Güresir E: Non-aneurysmal non-traumatic subarachnoid hemorrhage: patient characteristics, clinical outcome and prognostic factors based on a single-center experience in 125 patients. BMC Neurol 14:140, 2014

16. Konczalla J, Schuss P, Platz J, Vatter H, Seifert V, Güresir E: Clinical outcome and prognostic factors of patients with angiogram-negative and non-perimesencephalic subarachnoid hemorrhage: benign prognosis like perimesencephalic SAH or same risk as aneurysmal SAH? Neurosurg Rev 38:121-127, 2015

17. Naidech AM, Rosenberg NF, Maas MB, Bendok BR, Batjer $\mathrm{HH}$, Nemeth AJ: Predictors of hemorrhage volume and disability after perimesencephalic subarachnoid hemorrhage. Neurology 78:811-815, 2012

18. Ottosen TP, Schmidt M, Jacobsen JB, Stabel HH, Nielsen JF, Boetker HE, et al: Thirty-year trends in first-time hospitalization for subarachnoid hemorrhage and subsequent short- and long-term mortality: a Danish nationwide study. Cerebrovasc Dis 37 (Suppl 1):112, 2014 (Abstract)

19. Rinkel GJ, Wijdicks EF, Hasan D, Kienstra GE, Franke CL, Hageman LM, et al: Outcome in patients with subarachnoid haemorrhage and negative angiography according to pattern of haemorrhage on computed tomography. Lancet 338:964968,1991
20. Rinkel GJ, Wijdicks EF, Vermeulen M, Hasan D, Brouwers PJ, van Gijn J: The clinical course of perimesencephalic nonaneurysmal subarachnoid hemorrhage. Ann Neurol 29:463-468, 1991

21. Schmidt M, Johansen MB, Lash TL, Christiansen CF, Christensen S, Sørensen HT: Antiplatelet drugs and risk of subarachnoid hemorrhage: a population-based case-control study. J Thromb Haemost 8: 1468-1474, 2010

22. Schwartz TH, Solomon RA: Perimesencephalic nonaneurysmal subarachnoid hemorrhage: review of the literature. Neurosurgery 39:433-440, 1996

23. van Gijn J, van Dongen KJ, Vermeulen M, Hijdra A: Perimesencephalic hemorrhage: a nonaneurysmal and benign form of subarachnoid hemorrhage. Neurology 35:493-497, 1985

24. Wong GKC, Wun Tam YY, Zhu XL, Poon WS: Incidence and mortality of spontaneous subarachnoid hemorrhage in Hong Kong from 2002 to 2010: a Hong Kong hospital authority clinical management system database analysis. World Neurosurg 81:552-556, 2014

25. Woznica M, Rosahl SK, Berlis A, Weyerbrock A: Outcome correlates with blood distribution in subarachnoid hemorrhage of unknown origin. Acta Neurochir (Wien) 152:417422,2010

\section{Disclosures}

The authors report no conflict of interest concerning the materials or methods used in this study or the findings specified in this paper.

\section{Author Contributions}

Conception and design: Konczalla. Acquisition of data: Konczalla, Kashefiolasl, Brawanski, Platz. Analysis and interpretation of data: Konczalla. Drafting the article: Konczalla. Critically revising the article: Senft, Seifert, Platz. Reviewed submitted version of manuscript: Senft, Seifert, Platz. Approved the final version of the manuscript on behalf of all authors: Konczalla. Statistical analysis: Konczalla. Administrative/technical/material support: Kashefiolasl, Brawanski, Platz. Study supervision: Seifert, Platz.

\section{Correspondence}

Juergen Konczalla, Department of Neurosurgery, Goethe University Hospital Frankfurt, Schleusenweg 2-16, Frankfurt am Main 60528, Germany. email: J.Konczalla@med.uni-frankfurt.de. 